\title{
State of the art in esophagectomy: robotic assistance in the abdominal phase
}

\author{
Eline M. de Groot ${ }^{1} \cdot$ Lucas Goense $^{1} \cdot$ Jelle P. Ruurda ${ }^{1} \cdot$ Richard van Hillegersberg $^{1}$
}

Received: 17 July 2020 / Accepted: 7 December 2020 / Published online: 31 December 2020

(c) The Author(s) 2020

\begin{abstract}
Over the years, robot-assisted esophagectomy gained popularity. The current literature focused mainly on robotic assistance in the thoracic phase, whereas the implementation of robotic assistance in the abdominal phase is lagging behind. Advantages of adding a robotic system to the abdominal phase include robotic stapling and the increased surgeon's independency. In terms of short-term outcomes and lymphadenectomy, robotic assistance is at least equal to laparoscopy. Yet high quality evidence to conclude on this topic remains scarce. This review focuses on the evidence of robotic assistance in the abdominal phase of esophagectomy.
\end{abstract}

Keywords Robotics $\cdot$ Esophagectomy $\cdot$ Minimally invasive esophagectomy $\cdot$ RAMIE $\cdot$ Da vinci

\section{Introduction}

Esophagectomy with radical lymphadenectomy, generally combined with neoadjuvant therapy, is the main component of treatment for localized esophageal cancer [1,2]. Esophagectomy is a complex and invasive surgical procedure associated with a relatively high morbidity and mortality rate. Hence, during the last decade, there has been a vast development in novel minimally invasive techniques to enhance recovery and decrease postoperative complications [3].

Various approaches have been investigated (including; hybrid, fully minimally invasive and robot-assisted esophagectomy), each with its specific technical advantages and difficulties. In general, minimally invasive surgery results in faster recovery and lower morbidity, especially reduction of pulmonary complications [4-6]. However, conventional minimally invasive procedures can be technically demanding. The inability to articulate and the rigidity of the thoracoscopic instruments technically hinder proper mediastinal lymphadenectomy. As such, robot-assisted

Eline M. de Groot

e.m.degroot-26@umcutrecht.nl

$\triangle$ Richard van Hillegersberg

r.vanhillegersberg@umcutrect.nl

1 Department of Surgery, University Medical Center Utrecht, POBOX 85500, 3508 GA Utrecht, The Netherlands esophagectomy has gained popularity during the last decade as it offers a magnified three-dimensional vision, motion scaling, and articulating instruments, allowing precise dissection of the peri-esophageal tissue along all the vital structures. Moreover, its superiority over open esophageal surgery has been demonstrated in a randomized trial [6].

So far, most studies focused on robotic assistance in the thoracic phase of esophagectomy because of the advantages during mediastinal dissection. However, the potential advantages of robotic assistance in the abdominal phase of the procedure have rarely been reported. This is probably due to the technical limitations of the first robotic systems which were less suitable for the abdominal phase [7]. The current robotic systems are better equipped for maneuvers with large amplitude without collisions of the robotic arms allowing implementation in the abdominal phase.

This article reviews the advances and technical development in robot-assisted esophageal surgery, with an emphasis on the abdominal phase.

\section{The operation}

\section{Robotic 4-armed system}

In 2003, esophageal resection was performed with robotic assistance for the first time [8]. The robotic assistance was limited to the thoracic phase as this was considered to be 
the most difficult part to be performed thoracoscopically. Furthermore, the first generation of robotic systems was not constructed to navigate in the multiquadrant abdominal area. The more recent developed robotic system, the da Vinci Xi, does allow for multiquadrant surgery since it is equipped with instruments with more freedom of movement and designed to prevent the robotic arms from colliding. In addition, the robotic system is equipped with a fourth arm.

The abdominal phase performed with robotic assistance follows the same surgical steps when performed with laparoscopic assistance. The patient is placed in supine position after which 4 robotic ports are inserted $(3 \times 8 \mathrm{~mm}$ and $1 \times 12 \mathrm{~mm}$ ) (Fig. 1). In our center, we make 2 extra entrances; one $5 \mathrm{~mm}$ for the liver retractor and one $10 \mathrm{~mm}$ for the assistant port.

The lesser omentum is dissected with the Cautery Hook to expose and dissect the crus. Hereafter, the greater curvature and vasa brevia are transected using both Vessel Sealer and the Cautery Hook. The left gastric vein is transected with the vessel sealer and the left gastric artery is clipped with a hem-o-lock before it is divided. The lymph node dissection over the celiac trunk, hepatic, and splenic arteries concludes the abdominal dissection phase.

The creation of the gastric conduit requires optimal surgical proficiency as the fundus of the stomach is sensitive for

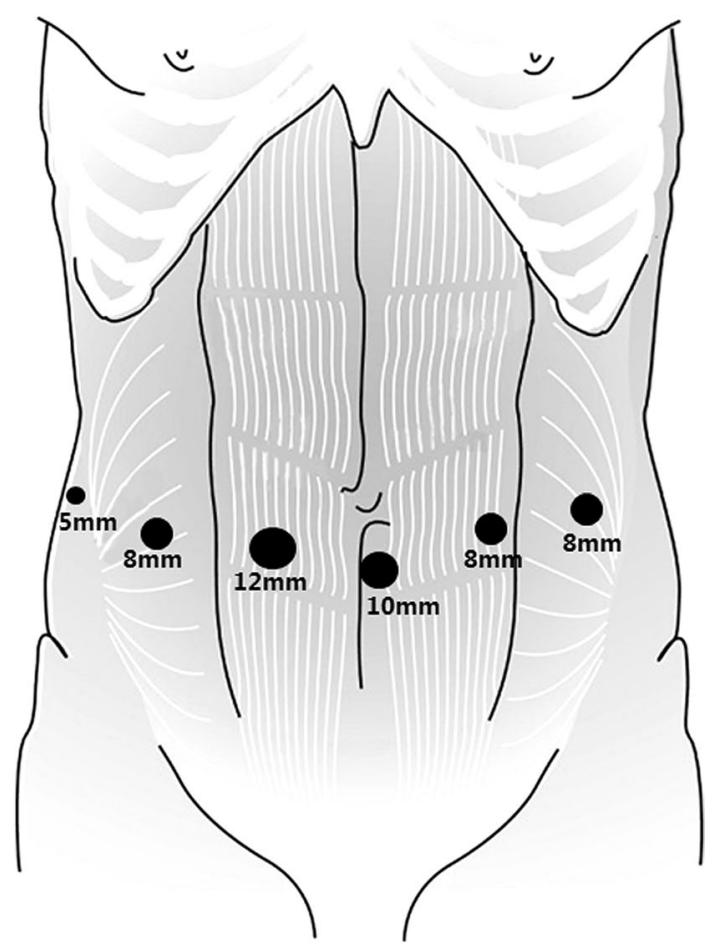

Fig. 1 Robotic port positioning of the abdominal phase during esophagectomy. The $10 \mathrm{~mm}$ port is used for the table assistant, the $5 \mathrm{~mm}$ port for the liver retractor and the $12 \mathrm{~mm}$ port for the camera. The other 3 ports are for robotic instruments damage due to grabbing or excessive touching [9]. A disadvantage of robotic assistance, in particular during this part of the surgery, may be the absence of tactile feedback. However, this is solved by lifting and retracting tissues mainly bluntly. Furthermore, robotic surgeons compensate by visual feedback of the tissue behavior upon touch.

In general, the gastric conduit is created by the use of an endowristed stapler device. This step is technically difficult with laparoscopy because challenging angles have to be made with the stapler. Robotic stapling overcomes this challenge. Robotic surgical tools and stapler devices allow endowristed movements leading to improved surgical dexterity as compared to laparoscopy. The stapler is fully wristed and can articulate up to 100 degrees left and right and more than 50 degrees up and down. Moreover, the stapler provides objective feedback and automatic tissue compression regarding clamp completion [10]. During stapling, the surgeon is able to control the camera, provide traction, and countertraction on the stomach and fire the stapler independently (Fig. 2). These advantages facilitate creation of the gastric conduit and avoid twist of the vertical stapler line by the exact positioning of the robotic staplers.

The surgeon's independency might be the greatest advantage of a robotic system over laparoscopy in the abdominal phase. During conventional laparoscopy, the surgeon is reliant on an assistant surgeon for both camera view and surgical assistance for the dissection. In particular hospitals where skilled assistants are scarce will benefit from this independency. Taking over these functions by robotic assistance does not fully eliminate table assistance since a robot-specialized scrub nurse remains a key component to successful esophagectomy as inserting and cutting sutures,

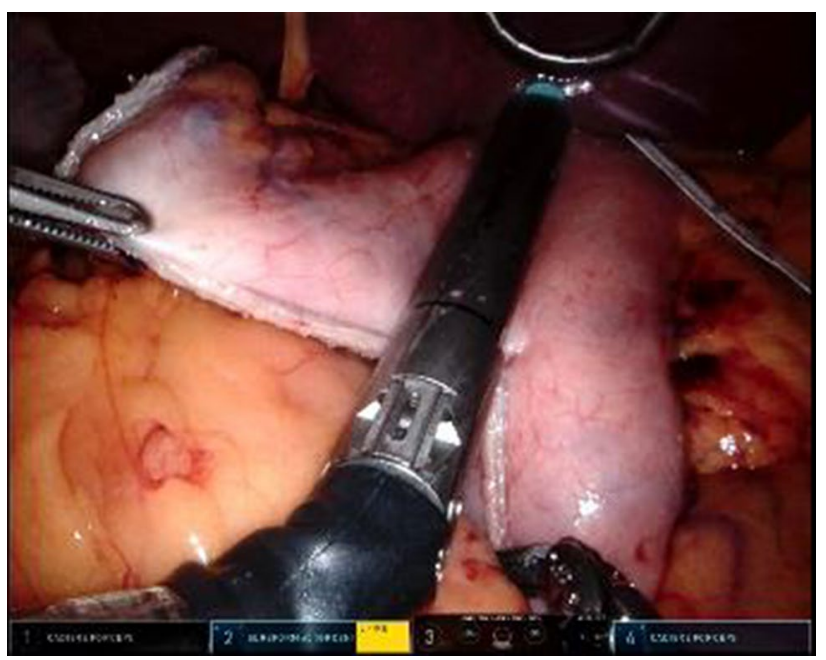

Fig. 2 Creation of the gastric conduit during robot-assisted esophagectomy using a 4-armed robotic system and an endowristed stapler device SureForm 60 (Intuitive Surgical Inc, Sunnyvale, CA) 
suctioning, delivery of lymph node stations, and replacing robotic cassettes are still necessary.

The benefits of the 4-armed robotic system for the thoracic phase have been published previously [11]. For the abdominal phase, the 4th arm is used for several purposes. It supports in counter traction by stretching tissue which allows the surgeon to dissect without the aid of an assistant surgeon. In addition, it could create a better exposure by grasping tissue away from the surgical field or it can be used for elevating the left liver lobe [12]. Given these multiple purposes of the $4^{\text {th }}$ arm, it ultimately maximizes the surgeon's autonomy and independency by taking over the aforementioned tasks which would otherwise be delegated to an assistant surgeon when operating without 4 arms.

Another important advantage of the robotic system is the dexterity in the lymphadenectomy.

\section{Oncological outcomes}

\section{Lymphadenectomy}

Several studies reported on the relevance of an adequate lymph node yield (LNY) during esophagectomy since a higher yield has been associated with increased survival $[13,14]$. Also on this topic most studies focused on thoracic LNY and only few studies report on abdominal LNY [15].

In general, lymph nodes are positioned around delicate structures such as the gastroduodenal ligament, gastric artery, hepatic artery, and splenic artery (Fig. 3). Robotic assistance can facilitate proper lymphadenectomy during this part of the procedure due to its technical advantages. A better visualization with a 3 -dimensional view, articulating instruments and tremor reduction technology aids in the dissection along these vital structures.

A high-quality lymphadenectomy is expressed in amount of retrieved lymph nodes plus the extent and completeness of the dissection. Regarding the quantity, one might question if the limit of abdominal LNY is already reached by laparoscopy and therefore might not need to improve any further.

Few studies have reported on the quantity of abdominal LNY, comparing robotic assistance to laparoscopy [16-19]. The results are shown in Table 1 . Out of the 4 propensity score matched studies, 1 study with 52 patients in both groups, found a significantly higher abdominal LNY with a robot-assisted approach (mean $9.7 \pm 6.4$ vs. $7.3 \pm 5.1$, $p=0.042$ ) [16]. The other 3 studies did not show any differences in LNY.

However, comparing LNY, especially between studies, is challenging. The determination of LNY is dependent on several factors as delivery and presentation of the lymph nodes to the pathologist. For example, significantly more

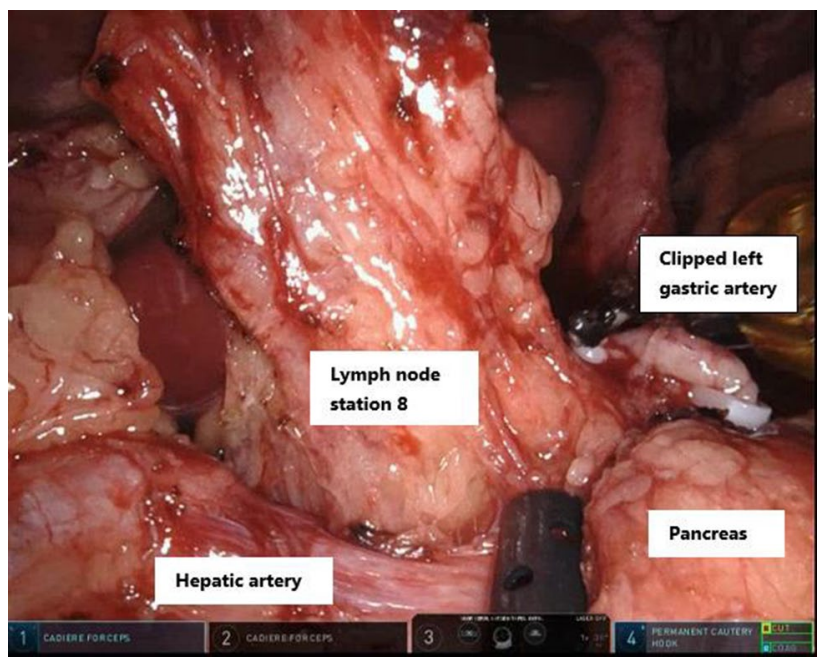

Fig. 3 Robot-assisted abdominal lymph node dissection during esophagectomy using a vessel sealer (Intuitive Surgical Inc, Sunnyvale, CA) in robotic arm 1 for lifting station 8 and a Cadiere or Cautery Hook (Intuitive Surgical Inc, Sunnyvale, CA) in arm 2 which could be exchanged during the dissection

lymph nodes could be counted when delivered in separate packages instead of en bloc resections [20].

In conclusion, the current evidence showed that robotic assistance contributes to at least an equal harvest of abdominal lymph nodes compared to laparoscopy.

The lymph node dissection could be aided by fluorescence techniques, yet this technology is still in its infancy. Injection of indocyanine green (ICG) in peritumoral tissue has shown to identify lymph nodes structures with a simple switch of camera mode. The camera of robotic systems is commonly equipped with a module for ICG imaging, whereas this is not the case in laparoscopic cameras. Since this technique is relatively new, evidence for esophageal use is scarce and only few studies published on this topic, mostly for gastric cancer [21-26]. A case-control study implemented ICG during robot-assisted gastrectomy in 40 patients and showed a significantly higher LNY in patients in which the ICG technique was applied [21]. Future studies should investigate whether ICG could add to the LNY in clinical practice during esophageal surgery.

Although the benefit of robotic assistance for the abdominal LNY is not yet convincing, the added value of a robotic system for mediastinal LNY during transhiatal esophagectomy is more explicit. This is mostly the result of the ability to dissect up to a higher level in the mediastinum with robotic instruments compared to laparoscopic tools. Several studies reported on robot-assisted transhiatal esophagectomy and stated that the procedure is safe and feasible [27-29]. However, high quality evidence is lacking to conclude on the added value of robotic assistance due to the retrospective nature of the studies and small study populations with a 


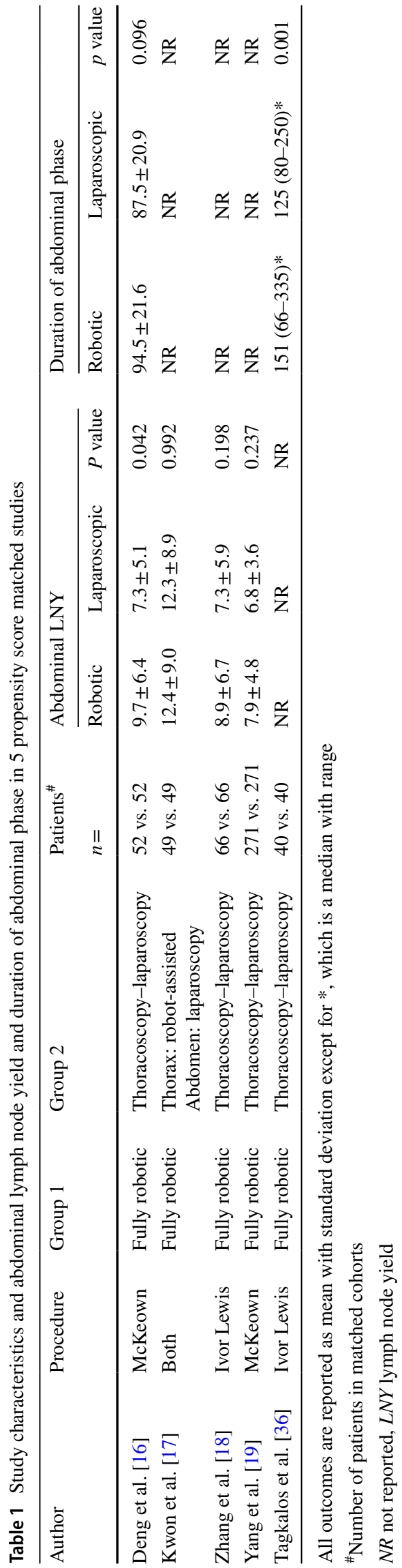

maximum of 40 patients. In addition, no studies exist comparing laparoscopic to robot-assisted transhiatal procedures.

Besides transhiatal procedures, transcervical esophagectomy appeals on a robot-assisted lower mediastinal lymphadenectomy trough abdominal access. Transcervical esophagectomy is a new approach in which an esophagectomy could be performed by cervical access and thereby avoiding thoracic access with all its consequences (i.e., single lung ventilation, thoracotomy). In general, this procedure is combined with a robot-assisted transhiatal procedure, mainly for lymphadenectomy of the lower and or middle mediastinum [30-33].

\section{Short-term outcomes}

\section{Postoperative complications}

The effect of the surgical approach on postoperative complications in the abdominal phase during esophagectomy has been previously reported $[34,35]$. Laparoscopy has resulted in a significant reduction of pulmonary complications compared to laparotomy. However, the effect of robotic assistance on short-term outcomes during the abdominal phase has not yet been clarified and only few studies have compared short-term outcomes between robotic assistance in the abdominal phase and laparoscopy [16-19,36,37]. Contrary, a recent review is published on gastric cancer, including multiple cohort studies comparing robot-assisted gastrectomy to laparoscopic gastrectomy stating that robotic assistance during gastrectomy is (oncologically) safe [38].

For esophageal surgery, 1 study by Kwon and colleagues looked specifically to the abdominal phase with the aim to assess the added value of robotic assistance compared to laparoscopy [17]. In that study, the thoracic phase was performed by robotic assistance in both groups. After propensity scored matching, Kwon et al. included 49 patients in both groups with comparable baseline characteristics. Postoperative overall complication rate, anastomotic leakage and respiratory complications were equal between both groups. In addition, abdomen related complications including chyloperitoneum also did not differ between both groups.

All other studies compared fully robotic esophagectomy to video-assisted esophagectomy which involved thoracoscopy and laparoscopy. Consequently, it is hard to distinguish which phase, or combination, caused the outcomes.

None of these studies, found any significant differences in postoperative complications. Only Yang et al., comparing 271 patients in each group, reported a significant higher rate of liver dysfunction after thoracoscopic-laparoscopic esophagectomy $(1.5 \%$ vs $0 \%, p=0.045)$ [19]. In addition to postoperative complications, duration of hospital stay was equal between both groups in all the studies. Tagkalos et al. 
showed that intensive care stay was decreased by 1 day after fully robot-assisted esophagectomy ( 1 vs. 2 days, $p=0.029$ ) when compared with conventional laparoscopy. However, this outcome was equal in the other studies [36].

Concluding, with the current evidence, robotic assistance in the abdominal phase during esophagectomy is not associated with a decrease nor increase in postoperative complications. However, no data regarding gastric conduit necrosis or leakage at the side of the staple line are reported. These outcomes could be relevant since they are related to the creation of the gastric conduit.

\section{Operation time}

It is likely that duration of surgery will initially increase during the implementation of robotic assistance in the abdominal phase because of its novelty. Two studies compared the duration of the abdominal phase with robotic assistance and laparoscopy.

Tagkalos et al. reported a duration of 151 min with robotic assistance and $125 \mathrm{~min}$ with laparoscopy $(p=0.001)$ [36]. It is not mentioned if the potential learning curve was already completed or if the robot procedures are the first cases with robotic assistance.

Contrary, Deng et al. did not show a significant difference in duration of surgery between both groups ( 95 vs. $88 \mathrm{~min}$, $p=0.096$ ), whereas this study stated that the initial experience of robotic-assisted esophagectomy was reported [16].

Even though these data are ambiguous, it is conceivable that a slightly prolonged operation time could be expected when a new technique is implemented. Zhang et al. published the initial results of fully robotic McKeown esophagectomy in 72 patients and compared the results of the first 26 patients (group 1) to the following 46 patients (group 2) [40]. It took a median of 18 min (range 9-35) in the first 26 patients and 15 min (range 10-21) in the consecutive 46 patients for setting up and docking the robot in the abdominal phase $(p=0.015)$. The median abdominal console time was $67 \mathrm{~min}$ (range 40-235) in group 1 and 55 min (range 35-104) in group $2(p=0.003)$. In addition, specific CUSUM analyses for the learning curve regarding the duration of the abdominal phase were performed. The CUSUM plots revealed decreasing docking time at case 16 and decreasing console time after case 14 .

\section{Proctoring}

A dedicated proctoring program is essential for implementing a robotic system in esophageal surgery. The question whether it is safer to start with the implementation of a robotic system in the thoracic or abdominal phase is under debate. Based on the aforementioned studies reporting on short-term outcomes, it seems that adding robotic assistance to the abdominal phase effects duration of surgery during its implementation period but does not increase postoperative complications. In addition, CUSUM plots regarding operation time decrease at case 24 in the thoracic phase and case 14 in the abdominal phase [39]. The implementation of robotic surgery might be less risky in the abdominal phase compared to the thoracic phase since the abdominal phase involves less danger zones with vital structures. However, the abdominal phase also consists several difficulties. In particular, the creation of adequate exposure is challenging due to the multiquadrant surgical field. In addition, despite the new generation of robotic systems, colliding of the robotic arms is more common in the abdominal phase as compared to the thorax.

In favor of the thoracic phase, the surgery is more standardized and consists of a well-arranged step-by-step procedure which makes it suitable for a structured training pathway. Other factors playing a role in this debate are type of surgeon and their previous experiences with minimally invasive procedures. For instance, a general surgeon is likely to be more comfortable in the abdomen than a thoracic surgeon. Regarding experiences, the transition from conventional minimally invasive surgery to robotic surgery is generally smoother as compared to the transition of open surgery to robotic surgery.

In conclusion, when implementing a robotic system, the preferred phase to start proctoring differs per situation and experience.

\section{Jejunostomy}

Jejunostomy placement is an optional step of an esophagectomy procedure, which is frequently performed to enable postoperative enteral tube feeding. Our recent literature review showed that jejunostomy tube feeding is probably preferable over nasoenteric tube feeding, as the former seems to be associated with less tube dislocations and better short-term quality of life [40-42]. However, jejunostomyrelated morbidity should be acknowledged and prevented as much as possible. Intestinal torsion at the jejunostomy site represents a particularly troublesome complication, which has a reported incidence between 0 and $17 \%$ and usually requires a re-operation $[43,44]$. An attempt to minimize this complication is made by fixating the jejunum to the abdominal wall at a second fixation point with antirotation stitches.

When creating the jejunostomy, the camera should be repositioned to focus on the left side of the abdominal wall using the same port positioning. No redocking of the robotic arms is necessary. Only the camera position is changed from arm 3 to arm number 2 and the 30-degree scope is turned upwards. Arm number 1 is still used for the Cadiere forceps and arm 3 for the Needle driver (port of arm 3 is retracted to the abdominal wall to allow wristed movement to the near 


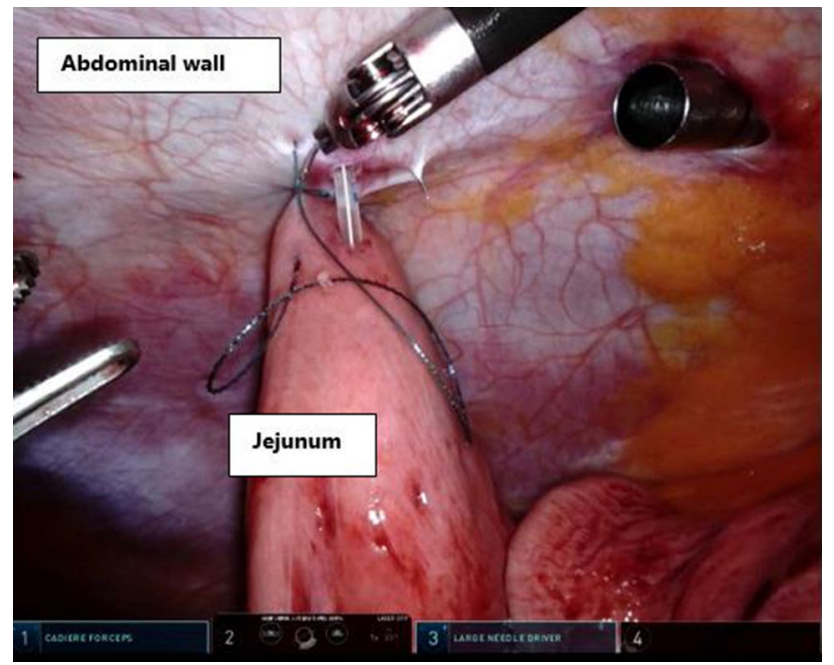

Fig. 4 Robot-assisted creation of jejunostomy during esophagectomy using articulating instruments to fixate the jejunum to the abdominal wall. Robotic arm 1 is used for the Cadiere forceps, arm 2 for the camera, and arm 3 for the Needle driver. Arm 4 is not used

target). Arm 4 is not used in this phase. The use of a robotic system for creating a jejunostomy facilitates reliable purse string suturing of the jejunum to the abdominal wall using a barbed suture (V-Lock, Medtronic, USA).

This jejunostomy technique can be challenging during conventional laparoscopy, since the working angle that is oriented towards the abdominal wall is not ideal. Robotic surgery increases the surgeons' dexterity by the use of wristed instruments and thereby facilitates suturing during the jejunostomy placement (Fig. 4).

\section{Costs}

The costs of a robotic system have been widely discussed. As discussed previously in this paper, it is unlikely that a robotic system will be specifically purchased for the abdominal phase during esophageal surgery. In case the robot is already used for the thoracic phase, it is probably cost saving to perform both the abdominal phase and the thoracic phase with robotic assistance. The same instruments could be used in both phases, whereas for laparoscopy an extra set of instruments is necessary. Besides surgical tools, it might be possible to reduce costs by saving on extra personal during the procedure.

However, the purchase of a robotic system and its maintenance remains expensive. For the thoracic phase, it might be suggested that these costs will possibly be equalized by reducing postoperative complications after robot-assisted esophagectomy compared to open esophagectomy [6]. With the current evidence, it is not likely that adding a robotic system in the abdominal phase will decrease postoperative complications as compared to laparoscopy.

Therefore, in terms of costs, robotic assistance in the abdominal phase is probably only cost saving if both thoracic and abdominal phases are performed with robotic assistance.

\section{Concluding remarks}

The current evidence of the added value of robotic assistance in the abdominal phase is still minimal. The benefits rely mostly on surgeons' perspective, for example, the independency of the surgeon and improved preciseness of dissection regarding stapling and lymph node dissection. The implementation of robotic assistance in the abdominal phase seems to be possible with a relatively limited learning curve and without compromising on short-term outcomes. Therefore, with the current evidence, robotic assistance in the abdominal phase during esophagectomy is at least not inferior to laparoscopy. Future prospective studies should reveal whether a robotic system will be worthwhile for the abdominal phase or even become superior over laparoscopy.

Author contributions All authors contributed to this article.

Funding No funding is received for this article.

\section{Compliance with ethical standards}

Conflict of interest JR and $\mathrm{RvH}$ are both proctors for Intuitive Surgical Inc, Sunnyvale, CA.

Research involving human participants and/or animals This article does not contain any studies with human participants or animals.

Informed consent Informed consent was not applicable to this review.

Open Access This article is licensed under a Creative Commons Attribution 4.0 International License, which permits use, sharing, adaptation, distribution and reproduction in any medium or format, as long as you give appropriate credit to the original author(s) and the source, provide a link to the Creative Commons licence, and indicate if changes were made. The images or other third party material in this article are included in the article's Creative Commons licence, unless indicated otherwise in a credit line to the material. If material is not included in the article's Creative Commons licence and your intended use is not permitted by statutory regulation or exceeds the permitted use, you will need to obtain permission directly from the copyright holder. To view a copy of this licence, visit http://creativecommons.org/licenses/by/4.0/. 


\section{References}

1. Shapiro J, van Lanschot JJB, Hulshof MCCM, van Hagen P, van Berge Henegouwen MI, Wijnhoven BPL et al (2015) Neoadjuvant chemoradiotherapy plus surgery versus surgery alone for oesophageal or junctional cancer (CROSS): Long-term results of a randomised controlled trial. Lancet Oncol. https://doi.org/10.1016/ S1470-2045(15)00040-6

2. van der Sluis PC, Ruurda JP, Verhage RJJ, van der Horst S, Haverkamp L, Siersema PD et al (2015) Oncologic long-term results of robot-assisted minimally invasive thoraco-laparoscopic esophagectomy with two-field lymphadenectomy for esophageal cancer. Ann Surg Oncol. https://doi.org/10.1245/s1043 4-015-4544-X

3. Haverkamp L, Seesing MFJ, Ruurda JP, Boone J, van Hillegersberg R (2017) Worldwide trends in surgical techniques in the treatment of esophageal and gastroesophageal junction cancer. Dis Esophagus. https://doi.org/10.1111/dote.12480

4. Takeuchi H, Miyata H, Ozawa S, Udagawa H, Osugi H, Matsubara $\mathrm{H}$ et al (2017) Comparison of short-term outcomes between open and minimally invasive esophagectomy for esophageal cancer using a nationwide database in Japan. Ann Surg Oncol. https:// doi.org/10.1245/s10434-017-5808-4

5. Sarkaria IS, Rizk NP, Goldman DA, Sima C, Tan KS, Bains MS et al (2019) Early quality of life outcomes after robotic-assisted minimally invasive and open esophagectomy. Ann Thorac Surg. https://doi.org/10.1016/j.athoracsur.2018.11.075

6. van der Sluis PC, van der Horst S, May AM, Schippers C, Brosens LAA, Joore HCA et al (2019) Robot-assisted minimally invasive thoracolaparoscopic esophagectomy versus open transthoracic esophagectomy for resectable esophageal cancer: a randomized controlled trial. Ann Surg. https://doi.org/10.1097/SLA.00000 00000003031

7. van Hillegersberg R, Seesing MFJ, Brenkman HJF, Ruurda JP (2017) Roboterassistierte minimal-invasive Ösophagektomie. Chirurg. https://doi.org/10.1007/s00104-016-0200-7

8. Van Hillegersberg R, Boone J, Draaisma WA, Broeders IAMJ, Giezeman MJMM, Rinkes IHMB (2006) First experience with robot-assisted thoracoscopic esophagolymphadenectomy for esophageal cancer. Surg Endosc Other Interv Tech. https://doi. org/10.1007/s00464-005-0674-8

9. Laméris W, Eshuis WJ, Cuesta MA, Gisbertz SS, van Berge Henegouwen MI (2019) Optimal mobilization of the stomach and the best place in the gastric tube for intrathoracic anastomosis. $\mathrm{J}$ Thorac Dis https://doi.org/10.21037/jtd.2019.01.28

10. Johnson CS, Kassir A, Marx DS, Soliman MK (2019) Performance of da Vinci Stapler during robotic-assisted right colectomy with intracorporeal anastomosis. J Robot Surg. https://doi. org/10.1007/s11701-018-0828-z

11. Grimminger PP, Hadzijusufovic E, Ruurda JPH, Lang H, Van Hillegersberg R (2018) The da vinci Xi robotic four-arm approach for robotic-assisted minimally invasive esophagectomy. Thorac Cardiovasc Surg. https://doi.org/10.1055/s-0038-1636933

12. Grimminger PP, Hadzijusufovic E, Babic B, Van Der Sluis PC, Lang H (2020) Innovative fully robotic 4-arm Ivor Lewis esophagectomy for esophageal cancer (RAMIE4). Dis Esophagus. https://doi.org/10.1093/dote/doz015

13. Visser E, Rossum PSNV, Ruurda JP, Van HR (2017) Impact of lymph node yield on overall survival in patients treated with neoadjuvant chemoradiotherapy followed by esophagectomy for cancer. Ann Surg. https://doi.org/10.1097/SLA.0000000000002389

14. Samson P, Puri V, Broderick S, Patterson GA, Meyers B, Crabtree $\mathrm{T}$ (2017) Extent of lymphadenectomy is associated with improved overall survival after esophagectomy with or without induction therapy. Ann Thorac Surg. https://doi.org/10.1016/j.athoracsur .2016.08.010

15. Phillips AW, Lagarde SM, Navidi M, Disep B, Griffin SM (2017) Impact of extent of lymphadenectomy on survival, post neoadjuvant chemotherapy and transthoracic esophagectomy. Ann Surg. https://doi.org/10.1097/SLA.0000000000001737

16. Deng HY, Luo J, Li SX, Li G, Alai G, Wang Y et al (2019) Does robot-assisted minimally invasive esophagectomy really have the advantage of lymphadenectomy over video-assisted minimally invasive esophagectomy in treating esophageal squamous cell carcinoma? A propensity score-matched analysis based on shortterm. Dis Esophagus. https://doi.org/10.1093/dote/doy110

17. Na KJ, Park S, Park IK, Kim YT, Kang CH (2019) Outcomes after total robotic esophagectomy for esophageal cancer: A propensitymatched comparison with hybrid robotic esophagectomy. J Thorac Dis https://doi.org/10.21037/jtd.2019.11.58

18. Zhang Y, Han Y, Gan Q, Xiang J, Jin R, Chen K et al (2019) Early outcomes of robot-assisted versus thoracoscopic-assisted ivor lewis esophagectomy for esophageal cancer: a propensity score-matched study. Ann Surg Oncol. https://doi.org/10.1245/ s10434-019-07273-3

19. Yang Y, Zhang X, Li B, Hua R, Yang Y, He Y et al (2020) Shortand mid-term outcomes of robotic versus thoraco-laparoscopic McKeown esophagectomy for squamous cell esophageal cancer: a propensity score-matched study. Dis Esophagus. https://doi. org/10.1093/dote/doz080

20. Veeramachaneni NK, Zoole JB, Decker PA, Putnam JB, Meyers BF (2008) Lymph node analysis in esophageal resection: american college of surgeons oncology group Z0060 trial. Ann Thorac Surg. https://doi.org/10.1016/j.athoracsur.2008.04.043

21. Kwon IG, Son T, Kim H Il, Hyung WJ (2019) Fluorescent Lymphography-Guided Lymphadenect omy during Robotic Radical Gastrectomy for Gastric Cancer. JAMA Surg https://doi. org/10.1001/jamasurg.2018.4267.

22. Herrera-Almario G, Patane M, Sarkaria I, Strong VE (2016) Initial report of near-infrared fluorescence imaging as an intraoperative adjunct for lymph node harvesting during robot-assisted laparoscopic gastrectomy. J Surg Oncol. https://doi.org/10.1002/ jso. 24226

23. Schlottmann F, Patti MG (2019) Esophageal adenocarcinoma lymphatic drainage with ICG fluorescence imaging. J Gastrointest Surg. https://doi.org/10.1007/s11605-018-3769-y

24. Kim TH, Kong SH, Park JH, Son YG, Huh YJ, Suh YS et al (2018) Assessment of the completeness of lymph node dissection using near-infrared imaging with indocyanine green in laparoscopic gastrectomy for gastric cancer. J Gastric Cancer. https://doi. org/10.5230/jgc.2018.18.e19

25. Helminen O, Mrena J, Sihvo E (2017) Near-infrared image-guided lymphatic mapping in minimally invasive oesophagectomy of distal oesophageal cancer. Eur J Cardio-Thoracic Surg. https://doi. org/10.1093/ejcts/ezx141

26. Hachey KJ, Gilmore DM, Armstrong KW, Harris SE, Hornick JL, Colson YL et al (2016) Safety and feasibility of near-infrared image-guided lymphatic mapping of regional lymph nodes in esophageal cancer. J Thorac Cardiovasc Surg. https://doi. org/10.1016/j.jtcvs.2016.04.025

27. Ruurda JP, Van Der Sluis PC, Van Der Horst S, Van Hilllegersberg R (2015) Robot-assisted minimally invasive esophagectomy for esophageal cancer: A systematic review. J Surg Oncol. https://doi. org/10.1002/jso.23922

28. Seto Y, Mori K, Aikou S (2017) Robotic surgery for esophageal cancer: Merits and demerits. Ann Gastroenterol Surg. https://doi. org/10.1002/ags3.12028

29. Washington K, Watkins JR, Jay J, Jeyarajah DR (2019) Oncologic resection in laparoscopic versus robotic transhiatal 
esophagectomy. J Soc Laparoendosc Surg. https://doi.org/10.4293/ JSLS.2019.00017

30. Egberts JH, Schlemminger M, Hauser C, Beckmann JH, Becker T (2019) Robot-assisted cervical esophagectomy (RACE procedure) using a single port combined with a transhiatal approach in a rendezvous technique: a case series. Langenbeck's Arch Surg. https://doi.org/10.1007/s00423-019-01785-y

31. Nakauchi M, Uyama I, Suda K, Shibasaki S, Kikuchi K, Kadoya S et al (2019) Robot-assisted mediastinoscopic esophagectomy for esophageal cancer: the first clinical series. Esophagus. https:// doi.org/10.1007/s10388-018-0634-8

32. Mori K, Yoshimura S, Yamagata Y, Aikou S, Seto Y (2017) Preclinical study of transcervical upper mediastinal dissection for esophageal malignancy by robot-assisted surgery. Int J Med Robot Comput Assist Surg. https://doi.org/10.1002/rcs.1750

33. Chiu PWY, de Groot EM, Yip HC et al. Robot-assisted cervical esophagectomy: first clinical experiences and review of the literature. Dis Esophagus 33(Supplement_2):doaa052. https://doi. org/10.1093/dote/doaa052

34. Mariette C, Markar SR, Dabakuyo-Yonli T Han S, Meunier B, Pezet D, Collet D, et al (2019) Hybrid minimally invasive esophagectomy for esophageal cancer. N Engl J Med https://doi. org/10.1056/NEJMoa1805101.

35. Messager M, Pasquer A, Duhamel A, Caranhac G, Piessen G, Mariette C (2015) Laparoscopic gastric mobilization reduces postoperative mortality after esophageal cancer surgery: A French nationwide study. Ann Surg. https://doi.org/10.1097/SLA.00000 00000001470

36. Tagkalos E, Goense L, Hoppe-Lotichius M, Ruurda JP, Babic B, Hadzijusufovic E et al (2019) Robot-assisted minimally invasive esophagectomy (RAMIE) compared to conventional minimally invasive esophagectomy (MIE) for esophageal cancer: a propensity-matched analysis. Dis Esophagus. https://doi.org/10.1093/ dote/doz060

37. Chen J, Liu Q, Zhang X, Yang H, Tan Z, Lin Y, et al (2019) Comparisons of short-term outcomes between robot-assisted and thoraco-laparoscopic esophagectomy with extended twofield lymph node dissection for resectable thoracic esophageal squamous cell carcinoma. J Thorac Dis https://doi.org/10.21037/ jtd.2019.09.05.
38. van Boxel GI, Ruurda JP, van Hillegersberg R (2019) Roboticassisted gastrectomy for gastric cancer: a European perspective. Gastric Cancer. https://doi.org/10.1007/s10120-019-00979-z

39. van der Sluis PC, Ruurda JP, van der Horst S, Goense L, van Hillegersberg R (2018) Learning curve for robot-assisted minimally invasive thoracoscopic esophagectomy: results from 312 cases. Ann Thorac Surg. https://doi.org/10.1016/j.athoracsur .2018.01.038

40. Berkelmans GHK, Wilts BJW, Kouwenhoven EA, Kumagai K, Nilsson M, Weijs TJ et al (2016) Nutritional route in oesophageal resection trial II (NUTRIENT II): Study protocol for a multicentre open-label randomised controlled trial. BMJ Open. https://doi. org/10.1136/bmjopen-2016-011979

41. Tao Z, Zhang Y, Zhu S, Ni Z, You Q, Sun X et al (2019) A prospective randomized trial comparing jejunostomy and nasogastric feeding in minimally invasive McKeown esophagectomy. J Gastrointest Surg. https://doi.org/10.1007/s11605-019-04390-y

42. Kingma BF, Ruurda JP, van Hillegersberg R (2020) Does jejunostomy tube feeding improve outcomes after esophagectomy? In: Ferguson M (ed) Difficult decisions in thoracic surgery. Difficult decisions in durgery: an evidence-based approach. Springer, Cham, pp 343-353. https://doi.org/10.1007/978-3-030-47404 $-1 \_29$

43. Kingma BF, Turchi MJ, Lovera R, Ramirez M, Badaloni A, Van Hillegersberg R, Ruurda JP NA. Technical notes and outcomes of robot-assisted and laparoscopic jejunostomy placement with anti-rotation fixation in esophagectomy. Submitted

44. Kitagawa H, Namikawa T, Iwabu J, Uemura S, Munekage M, Yokota K et al (2019) Bowel obstruction associated with a feeding jejunostomy and its association to weight loss after thoracoscopic esophagectomy. BMC Gastroenterol. https://doi.org/10.1186/ s12876-019-1029-6

Publisher's Note Springer Nature remains neutral with regard to jurisdictional claims in published maps and institutional affiliations. 